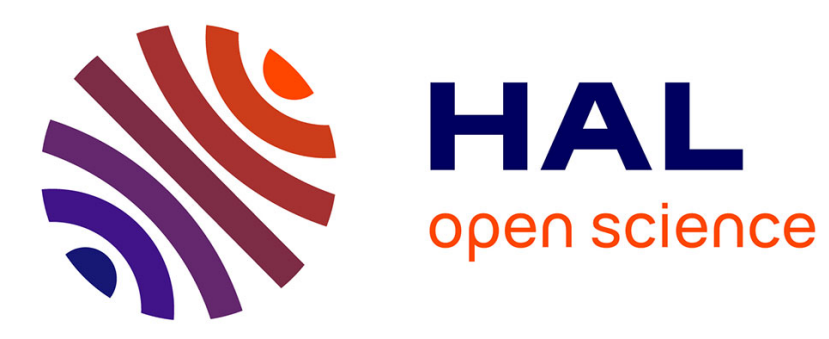

\title{
The contribution of Atomic Force Microscopy (AFM) in microalgae studies: A review
}

Irem Demir, Pascal Guiraud, Cécile Formosa-Dague

\section{To cite this version:}

Irem Demir, Pascal Guiraud, Cécile Formosa-Dague. The contribution of Atomic Force Microscopy (AFM) in microalgae studies: A review. Algal Research - Biomass, Biofuels and Bioproducts, 2021, 60, pp.102506. 10.1016/j.algal.2021.102506 . hal-03423286

\section{HAL Id: hal-03423286 \\ https://hal.science/hal-03423286}

Submitted on 15 Nov 2021

HAL is a multi-disciplinary open access archive for the deposit and dissemination of scientific research documents, whether they are published or not. The documents may come from teaching and research institutions in France or abroad, or from public or private research centers.
L'archive ouverte pluridisciplinaire HAL, est destinée au dépôt et à la diffusion de documents scientifiques de niveau recherche, publiés ou non, émanant des établissements d'enseignement et de recherche français ou étrangers, des laboratoires publics ou privés. 


\title{
The contribution of Atomic Force Microscopy (AFM) in microalgae studies: a review
}

\author{
Irem Demir-Yilmaz ${ }^{1,2}$, Pascal Guiraud ${ }^{1}$, Cécile Formosa-Dague ${ }^{1}$
}

${ }^{1} \mathrm{TBI}$, Université de Toulouse, CNRS, INRAE, INSA, Toulouse, France

${ }^{2}$ LAAS, Université de Toulouse, CNRS, Toulouse, France

*Corresponding author: Cécile Formosa-Dague, formosa@insa-toulouse.fr 


\begin{abstract}
Atomic force microscopy (AFM) has now become a major technology to study single cells in living conditions. It provides nanoscale resolution imaging capacities and is a sensitive force machine able to record piconewton-scale forces, thereby making it possible to gain insights into the nanomechanical properties and molecular interactions of cells. While an extensive number of studies on microorganisms have demonstrated the potential of AFM to understand complex phenomena at cell's interfaces, its use in microalgae studies remains limited. These recent years, microalgae have been the subject of a significant number of fundamental studies notably because of their capacity to convert light, water and inorganic nutrients into a biomass resource rich in value-added products. The existing literature reporting AFM use to understand microalgae cell morphology, their nanomechanical properties or their interactions with their environment give a large overview of the contribution AFM can bring into microalgae studies. In this review, we will first present the principles of AFM and the different possibilities it offers to characterize cells. Then in a second part, the contribution of AFM to understand the effects of environmental conditions and external stress on microalgae cells will be discussed. Finally, we will show how AFM can be used to probe the interactions of microalgae with their environment and how such fundamental studies can represent a basis to improve microalgae production systems. Overall, this review, the first on this topic, aims to highlight the opportunities that AFM technology can bring to this field of research.
\end{abstract}

\title{
Keywords
}

Atomic force microscopy, microalgae, cell nanostructure, nanomechanics, interactions 


\section{Introduction}

Microalgae are unique microorganisms able to convert light, water and inorganic nutrients into a biomass rich in value-added products such as proteins, polysaccharides, or lipids [1,2]. For this reason they have a great interest from a biotechnological point of view, and microalgae are nowadays cultivated and exploited in large-scale production systems [3]. But despite the promises of this resource, at the moment, exploiting the potential of microalgae at the industrial scale faces several challenges linked to the different steps of microalgae production (biomass growth, harvesting and down-stream extraction processes), that have made its development for the moment economically unviable [4]. Meeting these challenges has motivated a number of basic research studies aiming at answering fundamental questions on microalgae's cell physiology, on their response to different environments, on how to harvest them, disrupt them, or on how to enhance their potential through genetic engineering. It is indeed through the comprehension of these questions that it will be possible to find solutions to exploit microalgae at the industrial scale in a cost-effective way.

Basic research on microalgae has started as early as 1960, but it is really at the beginning of the years 2000s that the number of research publications has started to become significant. The graph presented in Figure 1 shows the number of studies on microalgae referenced by the Scopus database since 1960 (grey curve); each year the number of studies published on the topic increases, up to more than 3500 publications produced in 2020. This increasing number of publications clearly demonstrates the growing interest of scientists for these microorganisms and the need for more basic research on microalgae. Compared to other microorganisms, however these numbers remain quite low; for instance the search "bacteria" retrieves more than 69000 publications only for the year 2020; the microalgae field can still be considered as an emerging field of research. Traditionally, microalgae are mainly studied using molecular biology and genetic approaches, or chemical engineering approaches. Regarding cell imaging, optical and electron microscopy remain the gold standards techniques [5-7], although, a small, but significant number of studies also use other type of microscopies such as atomic force microscopy (AFM).

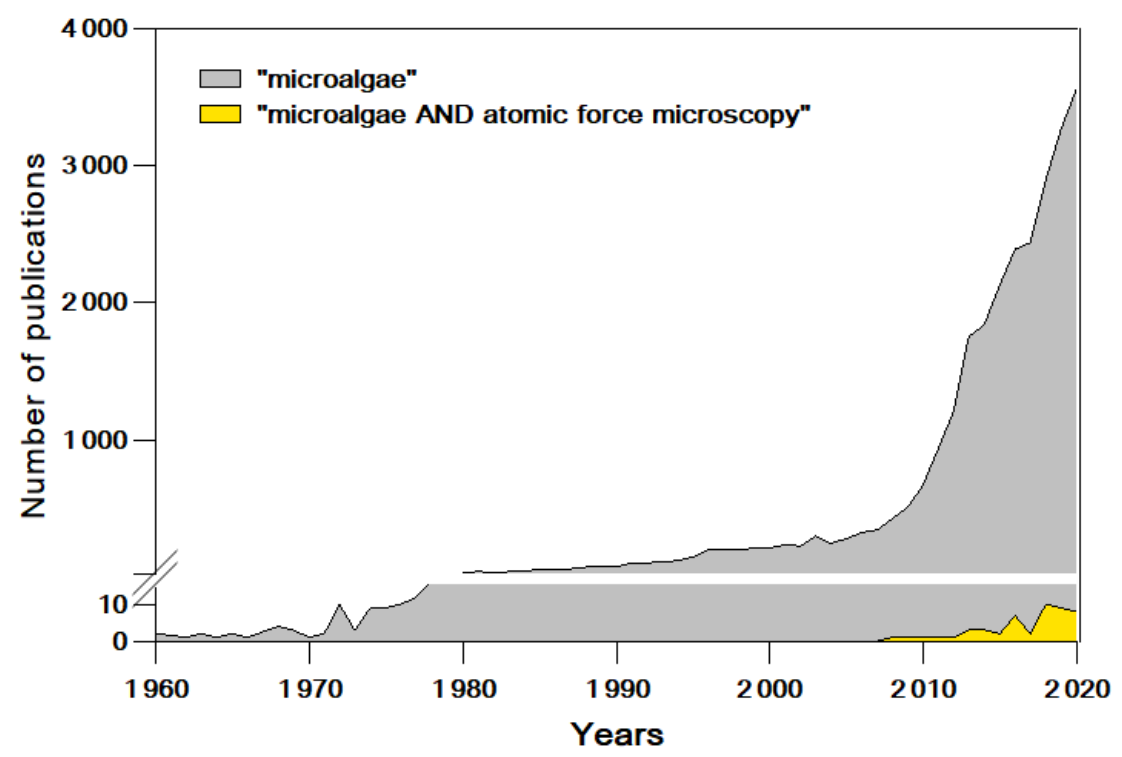

Figure 1. Microalgae studies published since 1960. Graphic representing the number of publications retrieved by entering the search "microalgae" (grey) or by entering the search "microalgae AND atomic force microscopy" (yellow) in the Scopus database (search within article titles, abstracts and keywords), from 1960 to 2020.

AFM, first developed in 1986 [8], relies on the control of a force acting between a sharp tip and a surface, while scanning a sample. This method is thus a surface probing method, making it different from other types of microscopies such as electron or optical microscopies. As the tip scans the surface of the sample, the cantilever on which it is fixed gets deflected. This deflection is recorded thanks to a laser reflected on a photodiode, thereby allowing to collect the signal. (figure 2) [9]. This 
technology is particularly well suited for the study of microorganisms under living conditions, as it has high-resolution imaging capacities, down to the nanometer scale, and is able to operate in liquid [10]. However, the potential of AFM does not limit to imaging; AFM is also a highly sensitive force machine, able to record forces as small as $20 \mathrm{pN}$. Indeed, AFM, in force spectroscopy mode, can record forcedistance curves, where the force experienced by the probe is plotted as a function of the probe-sample separation distance. These curves can then be interpreted through different physical models, thereby giving access to the nanomechanical and nanoadhesive properties of cell surfaces [10]. An important asset of AFM is that these quantified forces can be simultaneously localized at the surface of cells, which thus allows to correlate nanomechanics and molecular interactions with cell's surface ultrastructures [11]. Finally, the tips used for AFM imaging or force spectroscopy can be functionalized with living cells [12], biomolecules [13] or inert particles [14], which opens up new avenues to probe specific interactions between these functionalized tips and cell surfaces.

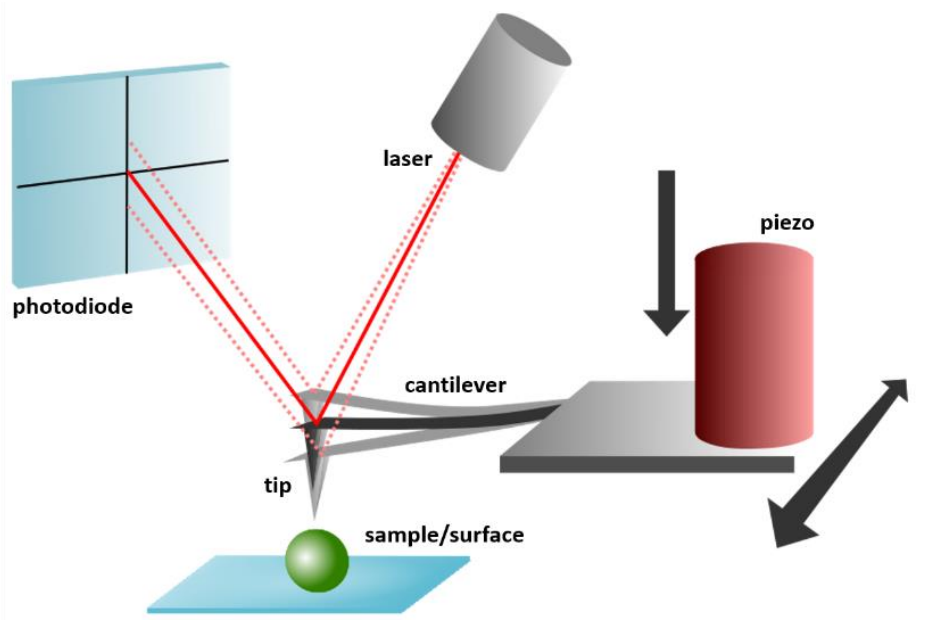

Figure 2. Atomic force microscopy principle. A sharp tip mounted on a cantilever can move in the $x, y$ and $z$ direction thanks to a piezo-electric ceramic. While scanning the sample, the deflection of the cantilever is recorded thanks to a laser reflected on a photodiode. Adapted from $[15,9]$.

While AFM has demonstrated over the years to be a powerful tool for microbiology studies $[15,16]$, its use to study microalgae still remains limited; as presented in figure 1 (yellow curve), the total number of microalgae studies using AFM is of 49 , which represents $0.17 \%$ of the total number of microalgae studies. Nevertheless, as for bacteria or yeasts, this technology could bring unique opportunities to understand cells, their morphology, their nanomechanical properties, their interactions with their environment, but also their response to different conditions such as environmental stress. In this work, we review the different studies where AFM was used as a principal tool to study microalgae cells; through these studies, we will describe the different possibilities of this technology, and the significant impact it can have on this field of research.

\section{AFM as a tool to characterize microalgae cells}

\subsection{Imaging of microalgae cells with nanoscale resolution}

One of the attractive advantages of AFM over other nanoscale microscopies is its ability to operate in liquid, which makes it possible to monitor live cells in real time. This provides the opportunity for direct visualization of cell surface morphology in physiologically relevant conditions. Different AFM modes can be used to image cell surfaces; contact mode or oscillating mode. In contact mode, the tip is in direct contact with the sample and scans it while maintaining the force constant. Although this allows providing high resolution images, in the case of soft samples, it is possible that the AFM tip deforms the surface during the scan, which may result in topographic images poorly associated with the deviations in height across the sample. In oscillating mode, the tip is oscillated near to its resonance frequency while scanning over the sample; the change in the oscillation amplitude 
reports on the surface topography. In this mode the tip is not in contact with the sample which reduces significantly the lateral forces that exist in contact mode. However in the case of biological samples with high electrolyte concentrations, interactions of the tip with low-range surface forces can impact the vibrating tip along its trajectory and modify the oscillation amplitude, which can result in sample deformation [17]. In the case of microalgae, contact mode is the principal imaging mode that has been used to characterize the morphology of cells. The first AFM images of diatoms were realized in 2001, where the nanostructure of the silica-based cell wall (valve or frustule) of live Pinnularia viridis (Nitzsch) Ehrenberg cells, was investigated [18]. In this study, the authors could show thanks to highresolution images that the cell wall was coated with a thick mucilaginous material. In addition, imaging of the cell's valves revealed silica nanostructures composed of conglomerates of packed silica spheres of approximately $45 \mathrm{~nm}$ of diameter. Later on in 2002, the same team also imaged the nanostructures present on the valve's surface of the diatom Craspedostauros australis, showing pores and rows in the girdle band region that forms the connecting region where the two valves of the diatom overlap. Then in 2003, the team of Gebeshuber and coworkers imaged the frustules of benthic freshwater diatom species, and could reveal the presence of an organic case enveloping the cells of approximately $10 \mathrm{~nm}$ of thickness [19]. Later in 2008, Francius and co-workers also used contact mode to image the three different morphotypes of the diatom Phaeodactylum tricornutum (fusiform, triradiate and oval, Figure 3A) [20]. Notably, the authors extracted quantitative information on the roughness of the cell surfaces thanks to high-resolution images and showed that the cell surface in the oval form is rougher than for the other two morphologies, which can be explained by the presence in this morphotype of excreted polymers on the surface. Finally, another team used contact mode to image the diatom species Cylindrotheca closterium (Figure 3B) and Cylindrotheca fusiform. The images produced in this case in air could show the morphological details of cells, such as girdle bands, raphe openings (siliceous structures present on the valve, which have slits running the longitudinal axis of the cell) or fibulae (silica arches that connect the raphe strips that border the raphe slit) (Figure 3B) [21,22]. Diatoms constitute an interesting group of microalgae, notably because of the large diversity of shapes and nanostructures present on the valves of these cells, which have been so far mostly explored using electron microscopy [23]. These studies show that AFM is also a suitable technique to characterize these morphologies, with the advantages of requiring minimum sample preparation compared to electron microscopy, as cells can be directly observed without any treatment. In addition, AFM imaging can also reveal the presence of organic layers around the cells, or polymers or mucilages, which can have important implications in the adhesive behavior of cells or in their mobility. While these studies are focused on diatoms, other microalgae species have also been imaged using AFM, such as Ventricaria ventricosa [24], C. vulgaris [25], or Dunaliella tertiolecta [26]. 

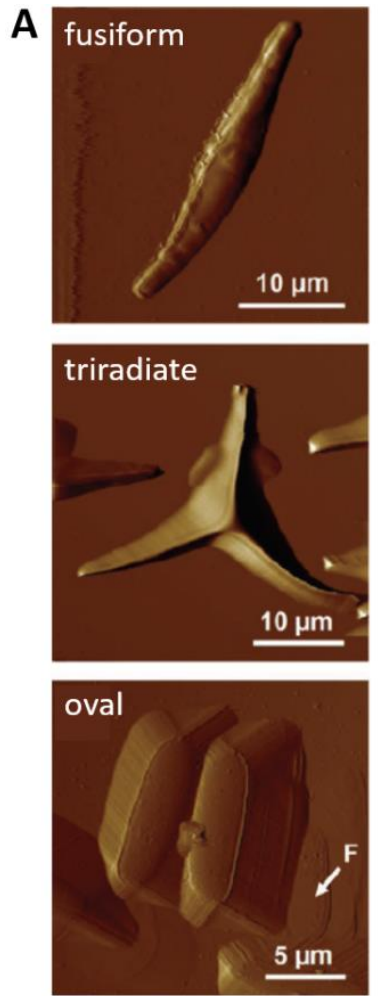

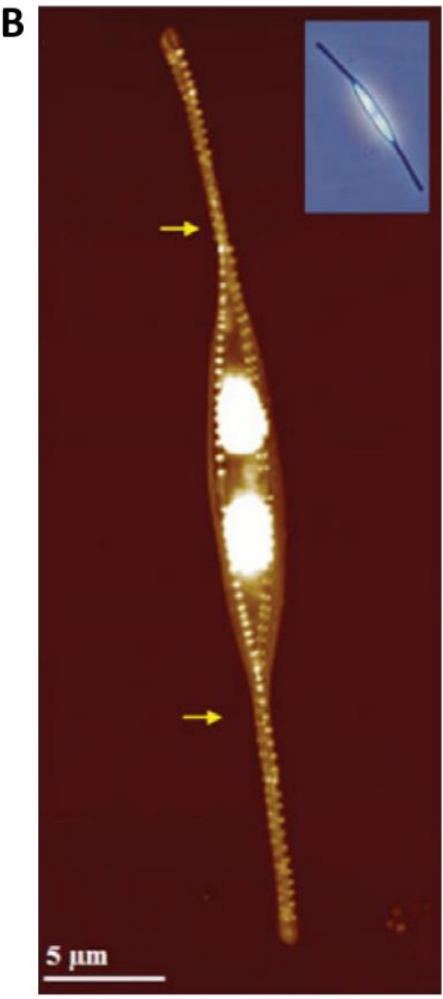

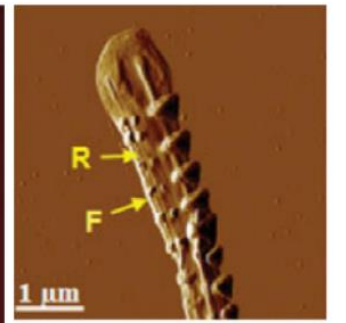
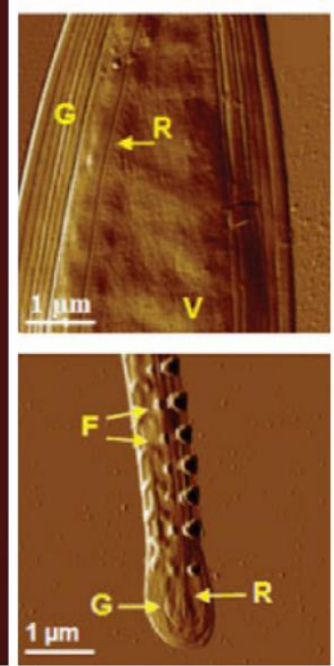

Figure 3. AFM imaging of diatoms. A) AFM deflection images of the diatom $P$. tricornutum morphotypes; fusiform, triradiate and ovoid. B) AFM images of the diatom $C$. closterium. Yellow arrows in the middle image indicate the spiral twist around the longitudinal cell axis. The inset shows a light microscopy image of the live cell. Deflection images (on the right) feature morphological details of cell wall: $V$, valve; $G$, girdle band; $R$, raphe opening; $F$, fibulae. Reprinted with permission from [20] and [21].

In addition to whole cells, AFM has also been used to visualize substances produced by microalgae, such as exopolysaccharides (EPS). EPS are complex polymers composed mainly of polysaccharides, that can also contain other components, for example protein moieties [27]. They have attracted a lot of interest because of their potential for industrial applications in food and health [28], and for these reasons they have been the focus of many studies, most of them dedicated to their chemical analysis by chromatography, mass spectrometry or nuclear magnetic resonance (NMR), among other techniques [27]. However, understanding EPS nanostructure thanks to AFM can also bring valuable information to further use them in specific applications. In this view, a study conducted by Cybulska and coworkers used AFM to characterize the EPS produced by the green microalgae Dictyosphaerium chlorelloides [29]. For that, the authors analyzed two different concentrations of the material, and showed that EPS formed a regular and porous matrix at higher concentration $(1 \mathrm{mg} / \mathrm{mL})$, whereas at low concentration $(10 \mu \mathrm{g} / \mathrm{mL})$, single molecules created a regular network containing interconnected polymers with numerous side chains and loops. Such findings thus showed that at high concentration, thanks to the porosity of the matrix formed, these EPS could for example be used to selectively immobilize particles [29]. In another study conducted in 2020, the EPS produced by Arthrospira platensis (Spirulina) were imaged using a force spectroscopy-based AFM imaging mode. In this mode, images are reconstructed by measuring the height of the contact point on force curves acquired on a matrix of points over the sample [30]. This type imaging has the advantage of reducing the lateral forces exerted by the tip in contact mode, where the tip scans laterally the sample while in contact with it. Moreover, force spectroscopy-based AFM imaging mode also offers the possibility to provide information on the nanomechanical and adhesive properties of the cells simultaneously. Using this mode, Vergnes and co-workers could show that the EPS produced by A. platensis formed a soft, adhesive gel in the medium surrounding the cells. Thanks to these information, the authors could conclude on the role of these EPS on cell flocculation and thus on the possibility to harvest them [31]. 


\subsection{Probing the nanomechanical properties of microalgae cells}

Besides its imaging capacities, AFM, as mentioned in the introduction, can also record forces in force spectroscopy mode, thereby giving access to the nanomechanical properties of cell surfaces, which can be a key aspect to understand fundamental aspects such as cell morphology, or for further microalgae application, for example to optimize cell disruption steps in production systems. For that, nanoindentation measurements are performed, in which a cantilever with known mechanical properties, is pushed against a sample at a defined force. This way, the resistance of the cell wall to the compression can be quantified, by extracting from the force curves obtained the cell wall spring constant (stiffness) or elasticity (Young's modulus, $\mathrm{Ym}$ ). These values are obtained by converting the force curves into force vs indentation curves by subtracting the deformation of the cantilever upon compression. Then these curves are analyzed using theoretical models such as the Hooke's law (stiffness), the Hertz model (Ym), or other appropriate models, depending on the shape of the tip and the type of the sample probed. Such nanomechanical measurements provide important information on the cell wall which is responsible for maintaining cell morphology, and which represents its interface with the surrounding environment. Notably it has been shown in multiple studies on different microorganisms that both the shape of the cells and the external conditions that cells undergo can greatly influence the cell wall nanomechanics $[32,33,15]$. For instance, in the study conducted by Francius et al., the authors also explored the nanomechanical properties of the three morphotypes of $P$. tricornutum using AFM force-indentation curves. Their results showed that the young modulus of the cell wall of cells in the oval form is five-fold higher than for the other two morphotypes, which constitute relevant information to gain insight into the mechanism leading to the different $P$. tricornutum morphotypes. With the same species, Formosa-Dague and co-workers in 2018 showed that the elasticity of the cell wall changes depending on the $\mathrm{pH}$ of the surrounding medium. Nanoindentation measurements performed in this study showed that the AFM tip was able to indent deeper into the cell wall at $\mathrm{pH} 8$ than at $\mathrm{pH} 10$; indeed, the cell wall $\mathrm{Ym}$ increased sevenfold at $\mathrm{pH} 10$ (Figure 4A) [14]. The same tendency was also observed in Chlorella vulgaris cells, a freshwater green microalgae species, where an increase of the $\mathrm{pH}$ from 6 to 8 resulted in a threefold increase of the rigidity of the cell wall of cells (Figure 4B) [25]. Changes in the nanomechanics of the cell wall often reflect changes in its composition or in its architecture, which can affect both the interactions of cells with their environment, as well as their shapes and deformability. For instance in the case of $P$. tricornutum, the important increase of the rigidity of cell's cell wall at $\mathrm{pH} 10$ has been associated with a better separation from water by flotation, possibly due to a better interaction between rigid fusiform cells with bubbles [14]. Another study conducted by Pillet and co-workers investigated the nanomechanical properties of Dunaliella tertiolecta in different phases of culture (exponential and stationary) [26]. In this case, the interesting point is that $D$. tertiolecta cells lacks a rigid cell wall and is instead enclosed in a thin plasma membrane covered by a mucous layer. Compared to other microalgae species, the resulting elasticity of cells was quite low, of $25 \mathrm{kPa}$ approximately, compared to $P$. tricornutum cells for which elasticities of $100-500 \mathrm{kPa}$ have been found $[20,14]$. The authors found that cells in stationary phase were even softer, with a Ym reduced by $40 \%$ compared to exponential phase, suggesting a molecular remodeling of the cell envelope upon aging (Figure 4C) [26]. Finally, as a last example, in a recent work conducted by Xiao et al. force spectroscopy experiments were performed directly on the external layers of different microalgae species. The force curves obtained by the authors led them to develop an analysis method based on a multiscale decomposition of derivative force-distance curves to quantify the elastic responses of these layers upon mechanical deformation. This work is interesting notably because thanks to this analysis method, it provides original information on the external layers protecting microalgae from their environment [34]. 

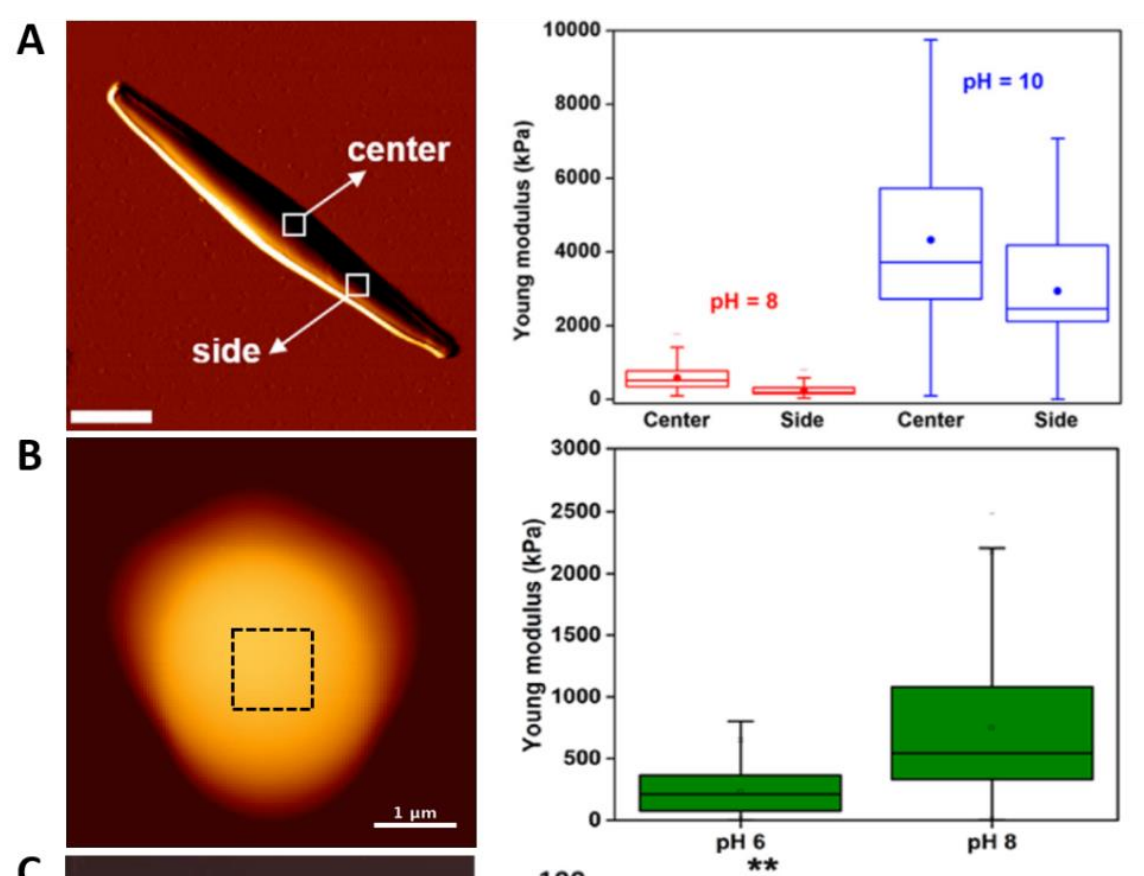

C
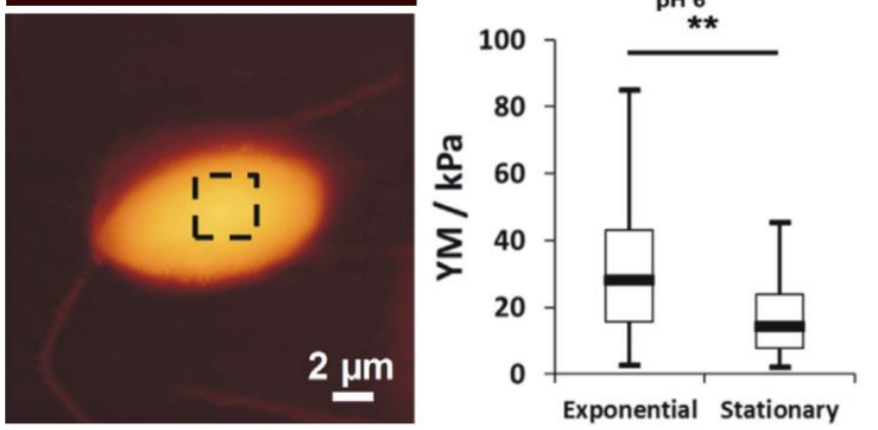

Figure 4. Nanomechanical properties of microalgae probed by AFM. A) AFM vertical deflection image of a $P$. tricornutum cell and box plot showing the distribution of $\mathrm{Ym}$ values obtained from force curves recorded on the center or on the side of cells at $\mathrm{pH} 8$ or $\mathrm{pH}$ 10. B) AFM height image of a $C$. vulgaris cell and box plot showing the distribution of $\mathrm{Ym}$ values measured on top of cells at pH 6 and 8. C) AFM height image of a $D$. tertiolecta cell in stationary phase and box plot showing the distribution of $\mathrm{Ym}$ values recorded on top of cells in exponential phase and stationary phase. Reprinted with permission from $[14,25,26]$.

\subsection{Probing the nanoadhesive properties of microalgae cells}

While nanomechanical properties of cells are retrieved by analyzing the approach part of force curves obtained in force spectroscopy, a lot of information can also be extracted from the retract parts, i. e. when the AFM tip is retracted from the sample to go back to its initial position. As the tip is retracted, if there is an interaction between the tip and a molecule at the surface of the sample, the molecule will unfold until the pulling force becomes stronger than the force of the interaction recorded. At this point, the interaction breaks, which is reflected on the force curve as a retract peak. The force at which the interaction was ruptured then informs about the strength of the interaction between the tip and the sample; the distance from the contact point at which the interaction breaks gives information on the length of the unfolded molecules and thus on their nature. Examples of such analysis have been provided as early as 2002, mainly by two different groups. The group of Gebeshuber and co-workers first investigated the adhesive properties of the freshwater diatom species Eunotia sudetica, and more specifically of the adhesive polymer cells produce at their surface to attach to substrates [35]. The force curves the authors recorded in this case showed multiple adhesion peaks with a sawtooth pattern, which they attributed to the successive unbinding of intra-chain loops from the adhesive, or to the successive release of inter-chain bonds holding a cross-linked multi-chain adhesive matrix together. Interestingly, the authors also suggested that these bonds, unfolded by the tip retracting, can rebond after several seconds, meaning that the adhesive is capable of "self-healing". In a further study in 2003, the same team also demonstrated that compared to a man-made adhesive (sticky tape), the diatom adhesive is more robust in a wet environment as over a period of several hours, no changes in the shape of the force curves recorded were observed [19]. Such experiments 
allowed to provide molecular scale information on the nanoadhesive properties of diatoms adhesives, useful for example to develop new and more powerful adhesives. In parallel, the group of Higgins et al. performed similar experiments on the adhesive mucilage strands secreted at the raphe region of the diatom C. australis [36]. In this case also, the authors could determine that the adhesive was very strong, and forces up to $60 \mathrm{nN}$ were needed to break its interactions with the tip. The next year, this same research group compared the interactions obtained with $C$. australis to those obtained with the adhesive excreted at the raphe region of another diatom species, Pinnularia viridis [37]. For both species the authors could observe multiple peaks on the force curves with a sawtooth pattern suggesting here also the successive unbinding of modular domains from the adhesive. In addition, the experiments revealed that the adhesive strands for both species were highly extensible and accumulated to form tethers. In this case also, such information on the molecular adhesive behavior of the polymers produced by cells could result in the development of new strong adhesive. Additionally, such information also informs on the mechanisms involved in cell attachment to a substrate, which allows cells to colonize habitats in natural environments. From a more general perspective, understanding the adhesive properties of microalgae cells thanks to AFM could also help optimizing processes in production systems, for example to control fouling phenomena taking place in bioreactors or at the surface of membranes used for cell separation.

Altogether these studies highlighted here show the potentialities of AFM to describe: (i) the nanoscale morphology of cells or of the EPS they excrete in the medium, (ii) their nanomechanical properties and so the architecture of their cell wall or membrane in different conditions, and (iii) the adhesive properties of polymers cells produce at their surface. The examples chosen here are rather descriptive of the different microalgae models, but they illustrate the potential AFM can have to understand fundamental processes taking place at their interfaces, for example in response to different conditions they experience in production processes or naturally in their environments. In addition, AFM being a label-free technique allowing to characterize samples in relevant environmental conditions, the data generated could be integrated into correlative approaches in order to provide even more encompassing data on microalgae.

\section{AFM as a tool to understand the effects of environmental conditions on microalgae cells}

\subsection{Effects of stress conditions on cells}

As the possibilities to use AFM techniques to characterize microalgae cells and their adhesive properties have emerged, more groups have used this technology to understand the effects of specific conditions on microalgae cell's surfaces. This is of particular interest to design efficient microalgae production systems, as for example stress conditions like culture conditions can greatly influence the production of certain molecules by the cells. In this view Yap and coworkers measured the nanomechanical properties of cells from the species Chlorococcum sp. in response to nitrogen deprivation [38]. $\mathrm{N}$-deprivation is a proven strategy for inducing triacylglyceride accumulation in microalgae, lipids that can be used for biofuel production for example. The results obtained in this study showed that the $\mathrm{Ym}$ of $\mathrm{N}$-deprived cells $(775 \mathrm{kPa}$ ) was approximately $30 \%$ higher than for $\mathrm{N}$ replete cells $(619 \mathrm{kPa})$. Thanks to TEM analysis of the thickness of the cell wall of cells, the authors suggested that this increase of the Ym could be directly correlated to an increase in the cell wall thickness in $\mathrm{N}$-deprived conditions. Although these specific culture conditions had an important impact on the cell wall, they did not affect the susceptibility of cells to mechanical rupture, which is an important aspect for the downstream processing of cells and extraction of the lipids. For instance a study by Lee et al. used AFM to determine the force needed to rupture cells, by indenting cells with an AFM tip [39]. This way the authors could show that the disruption energy needed varied depending on the location on the cell surface, and was on average of approximately $670 \mathrm{~J} / \mathrm{kg}$ of dry microalgae 
biomass. This value is much lower than the one required in existing mechanical cell disruption processes, such as hydrodynamic cavitation, which suggests that more efficient disruption processes could be developed [39]. Later in 2014, another study conducted by Warren et al. reported on the nanomechanical properties of Scenedesmus dimorphus in an aqueous and in dried state to provide information useful to develop efficient techniques for mechanical cell disruption [40]. Using nanoindentation measurements, the authors showed that the $\mathrm{Ym}$ of cells increased from approximately 2 to $58 \mathrm{MPa}$ from an aqueous state to a dried state, which can then orientate choices when designing a cell disruption process. Finally, besides biomass production and cell disruption, AFM has also contributed to understand the effects of flocculants used to harvest microalgae on their cell surface. For instance, Landels and co-workers used AFM to image Chlorella sorokiniana cells after harvesting by electro-coagulation flotation with $\mathrm{Al}(\mathrm{OH})_{3}$ used as a metal flocculant. Their results showed cells that were embedded into the $\mathrm{Al}(\mathrm{OH})_{3}$ hydrogel, which allows understanding how cells interact with the flocculant [41].

\subsection{Effects of changes in natural conditions}

But in addition to their potential for producing a wide variety of molecules in production systems, microalgae also play a fundamental role in aquatic ecosystems as they are the basis of aquatic food webs, on which many living organisms rely. Therefore understanding the effects of natural conditions is a key aspect. For example, environmental pollutants on microalgae cells is a subject of interest as this is how pollutants can enter food chains, which can be explored thanks to AFM. A first study in 2012 used AFM to investigate the effects of silver nanoparticles, which have toxic effects on algae cells, on the diatoms $C$. closterium and Cylindrotheca fusiformis and on their EPS [22]. AFM highresolution imaging experiments showed that the nanoparticles could penetrate the cell wall through the valve region of cells, and caused local damages inside the cell, notably in the chloroplasts region, without disintegration of the cell wall. In addition, the authors could also show that EPS production increased with nanoparticle exposure, and that the gel-like structure of EPS contained nanoparticles and aggregates of nanoparticles. This was an important finding of this study as the entrapment of these nanoparticles in the EPS produced by cells allows their persistence and accumulation in the water [22]. Then later in 2017, Nolte and co-workers investigated the effects of another type of nanoparticles that can be found in the environment, plastic nanoparticles (polystyrene), on the cell wall of the green microalgae species Pseudokirchneriella subcapitata [42]. In this study, AFM imaging of cells in interaction with plastics revealed that positively charged nanoparticles (bearing $-\mathrm{NH}_{2}$ functional groups) could adsorb at the cell surface, while negatively charged ones $(-\mathrm{COOH})$ resulted in a low cell coverage. The authors attributed this to the fact that positive particles could absorb on the cellulose present in the cell wall of $P$. subcapitata. Finally another type of pollutant, cadmium metal, was also investigated using AFM on different microalgae species; the green microalgae $D$. tertiolecta [43], and the diatoms $P$. tricornutum [44] and Nitzchia closterium [45]. Cadmium is recognized as a major pollutant of the marine environment, constituting a hazard to marine organisms. In 2019, the group of Ivosevic DeNardis and co-workers used AFM to probe the nanomechanical properties of $D$. tertiolecta cells in the presence of cadmium. The results showed that cells in the presence of cadmium had an increased stiffness of around $80 \%$ compared to control cells, which has consequences on their initial attachment to surfaces and on their deformation. Additional experiments performed in this study suggested that a different protein expression profile may be the cause of these changes in the cell surface properties under cadmium stress [43]. In parallel, another team also worked on cadmium stress, this time on the diatom $N$. closterium, and evaluated the influence of salinity on cadmium adsorption by the cells. Their results showed notably that a decreased salinity increased cell surface roughness, because of the presence at low salinity of silica particles on the cell surface (Figure 5A). This has for consequence to increase the specific surface area in cells, leading to a better adsorption of 
cadmium at low salinity [45]. Then in 2021, the same team worked on the effects this time of the cell morphotype of the diatom $P$. tricornutum on the cadmium adsorption on cells. In this study, AFM imaging combined with zeta potential measurements showed that the oval morphotype, which has a rougher and more negative surface compared to the triradiate and fusiform morphotypes, attracts more metal ions onto its surface (Figure 5B). The authors suggested that these different surface properties of oval cells may be related to their different cell wall composition compared to fusiform and triradiate cells, as determined by XPS analysis [44]. Altogether, in these studies on the effects of stress, AFM brings the opportunity to not only monitor the effects of pollutants on cells, but also to give insights into the mechanisms leading to pollutant adsorption by the cells. This is a major contribution of AFM as such fundamental data can be used to predict and evaluate the effects of various pollution in aquatic ecosystems.
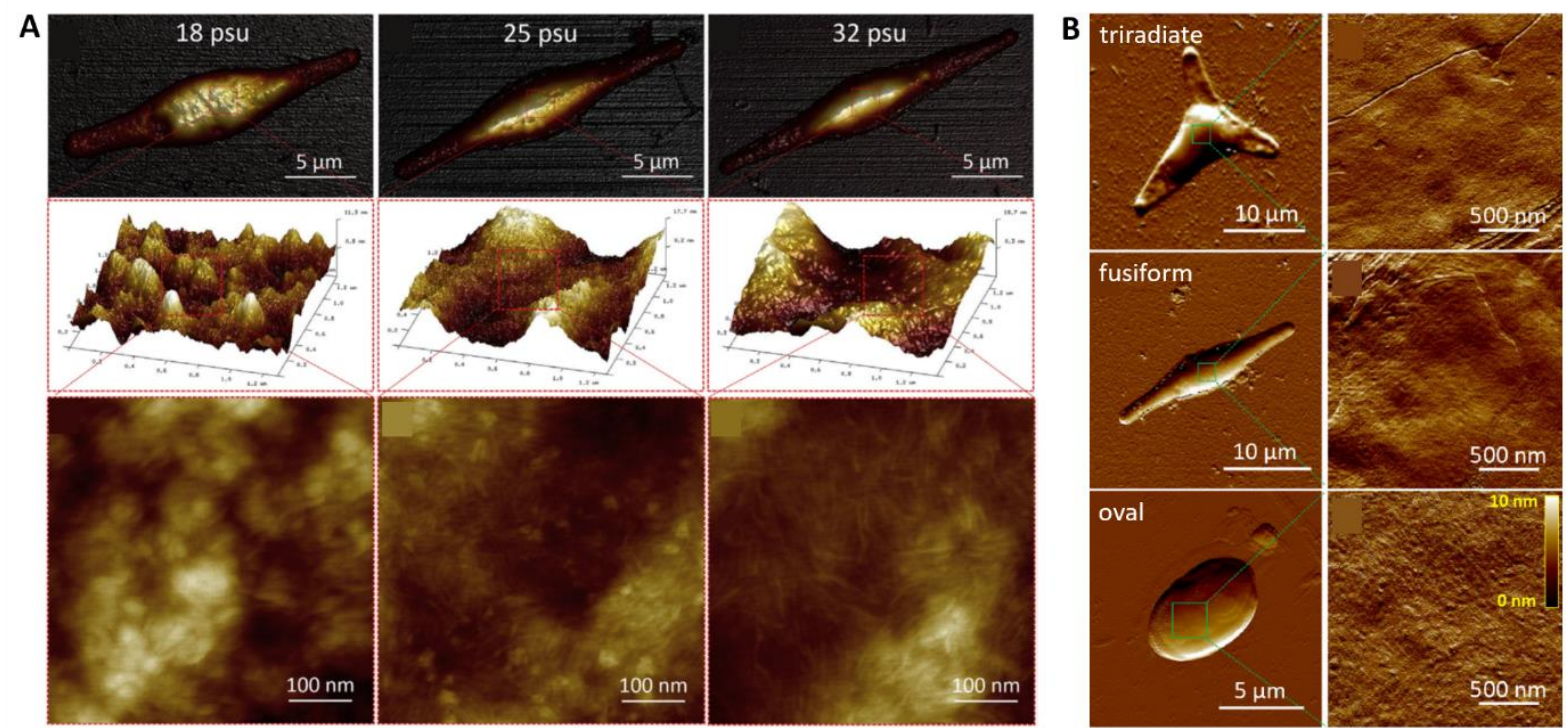

Figure 5. Influence of salinity or of cell morphotype on cadmium adsorption by cells. A) AFM height images of $N$. closterium cells acclimated at 18,25 , and $32 \mathrm{ps} \mu$ (first line) and amplified 3D morphology of typical difference in roughness on the cell walls of cells cultivated at these different salinities (middle line). AFM height images showing the nanoscale structures on the cell surfaces at the different salinities are presented in the third line. B) AFM vertical deflection images showing the morphology of the triradiate, fusiform, and oval morphotypes and their corresponding nanoscale cell wall topography (right column). Reprinted with permission from $[44,45]$.

\section{AFM to probe the interactions between cells and their environment}

As discussed earlier, AFM, thanks to its imaging and force probing possibilities, has proven to be a useful tool to probe the effects of environmental conditions on cells, or to understand how environmental conditions modify their responses to pollutants in aquasystems. In this part, we will now discuss how AFM can be used to understand the specific interactions between cells and surfaces or particles present in the environment. In a first study, Kreis and co-workers used a micropipette force spectroscopy technique to measure the adhesion forces between Chlalmydomonas reinhardtii flagella and silicon substrates [46]. In this case, the authors did not use a standard AFM set-up, but instead, they designed a micropipette force sensor with borosilicate glass capillaries that they used to pick-up single living cells (Figure 6A) and record forces through force spectroscopy experiments (Figure 6B). Using this set-up they could orientate cells and determine that only flagella could mediate adhesion to the substrates (Figure 6B). The force curves obtained showed that interestingly, this flagella-mediated adhesion could be reversibly switched on and off by light, in a timescale of seconds, and that the adhesion forces recorded varied depending on the illumination wavelength. Such findings may be used to control the adhesion properties of photoactive cells such as $C$. reinhardtii cells, and this way enhance culture efficiencies by inhibiting biofilm formation on photobioreactors surfaces [46]. 
A
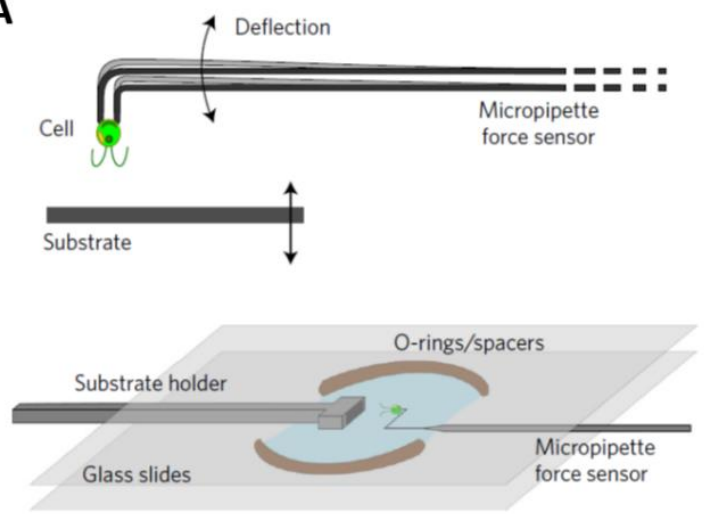

B

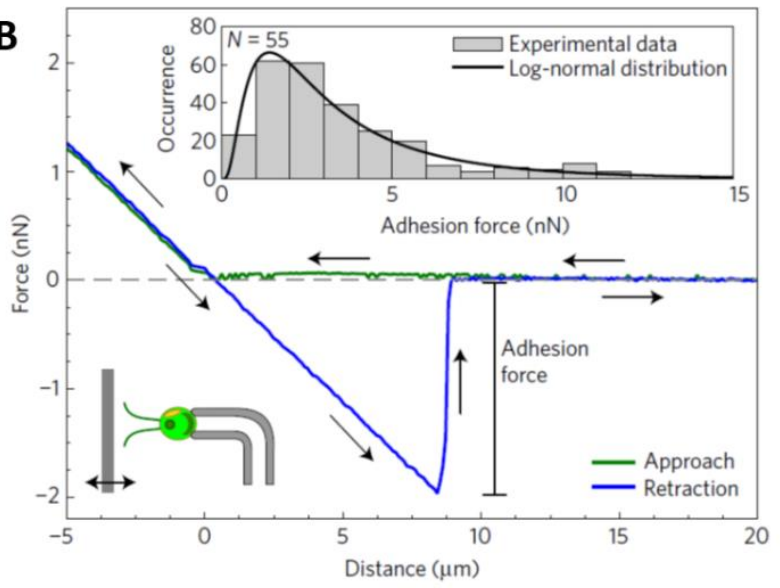

Figure 6. In vivo micropipette force spectroscopy of Chlamydomonas reinhardtii microalgae. A) Schematic representation of measurement principle and experimental set-up. B) Force distance curves obtained for cells orientated with their flagella in contact with the substrate. The adhesion force corresponds to the force needed to detach the cell from the substrate. Reprinted with permissions from [46].

Such strategy to measure the adhesion forces between single cells and substrates has also been used in a recent study conducted by Demir and co-workers [25]. In this study, instead of using a micropipette, the authors directly immobilized cells at the edge of tipless cantilevers, and probed their interactions with chitosan, a bio-sourced flocculant used for microalgae harvesting. So far the literature on chitosan-induced production in microalgae suggested a flocculation mechanism based on electrostatic interactions between negatively charged cells and chitosan, which is positively charged at a pH under its pKa (6.5). Thanks to the force spectroscopy experiments conducted in this study, the authors could show that in fact, the interactions between cells and chitosan did not rely on electrostatic interactions but rather on specific interactions between chitosan and specific polymers at the surface of cells. But interestingly, the authors found that this mechanism was taking place at low $\mathrm{pH}(6)$, but not at higher $\mathrm{pH}$. In this case, cells did not interact with chitosan anymore, but were instead flocculated by getting entrapped into the precipitate that chitosan forms at higher $\mathrm{pH}$. Such AFM experiments thus brought important information to generalize the use of chitosan-induced flocculation for microalgae harvesting [25]. With the same objective to understand flocculation mechanisms in microalgae, two other studies conducted by the same team showed that a same flocculant, magnesium hydroxide, could induce flocculation through different mechanisms in different microalgae species. Magnesium hydroxide results from the precipitation at high $\mathrm{pH}$ of magnesium ions present notably in marine waters. To understand the interactions between this flocculant and microalgae cells, the authors developed an original protocol to functionalize the AFM tips directly with magnesium hydroxide particles [14], and with these tips, they then probed the interactions with the surface of $P$. tricornutum [14] and D. salina cells [47]. Their results showed that while for $P$. tricornutum, magnesium hydroxide particles could directly interact with the cell surface through electrostatic interactions [14], in the case of $D$. salina, no interactions could be recorded, thereby suggesting another flocculation mechanism. Further experiments showed that indeed cells in this case were flocculated through a sweeping mechanism, i. e. by getting entrapped in a massive precipitate [47]. Then in these studies, AFM, by making it possible to access the interactions between cells and particles at the molecular scale, allowed to understand the complexity of flocculation mechanisms. Such knowledge could have an important impact to optimize efficient harvesting processes. 


\section{Perspectives outlooks and conclusions}

This review is a quite exhaustive view of what "conventional" AFM techniques can bring to the field of microalgae. However, other advanced techniques already used in studies focused on other types of microorganisms could also bring valuable information to further understand microalgae. Single-molecule force spectroscopy (SMFS) is one of these techniques. It consists in functionalizing AFM tips with biomolecules in order to study their interactions with specific molecules at the surface of cells. For instance, such tips modifications have been used to detect and locate a specific mannoprotein (Ccw12) at the surface of living yeast cells of Saccharomyces cerevisiae [13] or to understand the strength and dynamics of homotypic interactions mediated by a specific protein (SdrC) at the surface of bacterial cells of Lactococcus lactis [48]. Used in microalgae studies, SMFS could bring new information useful to understand cell adhesion for example, or to understand cell wall surface composition. Another example of an AFM advanced technique is chemical force microscopy (CFM), where gold coated tips are functionalized with hydrophobic thiols to probe the surface of cells. For instance, such strategy has been used to probe the hydrophobic properties of spores of Aspergillus fumigatus [49], or to show the role of glycopeptidolipids in the surface hydrophobicity of the bacteria Mycobacterium abscessus [50]. Although this technique has been used in one microalgae study [26], its general use could help researchers gain insights into the physico-chemical properties of microalgae cells depending on their environmental conditions.

Moreover, these recent years, new developments of original AFM techniques have emerged and offer exciting prospects for microalgae studies. One of these recent developments, FluidFM, combines AFM with microfluidics [51]. With this system, standard AFM cantilevers are replaced by microfluidic ones, which contain a microchannel that can be filled with liquid. A pressure controller connected to these cantilevers then allow to exert a positive or negative pressure inside the cantilever. In different fields, such technology has already been used for example to probe the interactions of single cells aspirated at the aperture of cantilevers [52,53], to aspirate liquids from a cell 's interior for further analysis $[54,55]$ or to create a microsized bubble to measure the hydrophobicity of single cells [56] . Such experiments applied to microalgae could help in analyzing the lipid profiles of different strains or in different conditions, which could bring valuable information to optimize culture conditions or microalgae strains. In this view another interesting development of AFM is its combination with a tunable infrared laser source (AFM-IR), which has allowed for Streptomyces cells to measure the size and map the distribution of oil inclusions inside cells [57]. Finally, new imaging techniques are emerging, such as high-speed AFM (HS-AFM), which makes it possible to acquire images on the surface of cells at a video rate. Recently, Evans and co-workers developed an immobilization procedure to apply HS-AFM to microalgae cells; this study represents an important basis to further image dynamic processes taking place at the surface of microalgae [58]. These few examples reflect on the recent technological advancements that are continuously made over the years with AFM, and suggest new and original questions that can be answered about microalgae.

Altogether, these AFM studies show the possibilities that such technology offers to answer fundamental questions on microalgae cells interfaces, on the effects of environmental or stress conditions on their nanoscale properties, and on their interacting behavior with their environment. Such fundamental questions need to be answered to exploit the potential of microalgae at industrial scales, and develop and optimize the different steps involved in production systems (production, harvesting, extraction). In addition, as we discussed, it is also a way to understand how microalgae in the environment can be affected by various pollutants that modern society produces. Although imaging is still the most common application of AFM in microalgae studies, force spectroscopy measurements to probe the nanomechanical or adhesive properties of cells have also demonstrated 
to bring new original information that can be useful to develop cost-effective processes for example for cell harvesting or cell disruption.

\section{Acknowledgements}

This work was performed thanks to a funding from Agence Nationale de la Recherche (ANR), JCJC project FLOTALG (ANR-18-CE43-000101). C.F.-D. is a researcher at CNRS.

\section{References}

[1] N. Pragya, K.K. Pandey, P.K. Sahoo, A review on harvesting, oil extraction and biofuels production technologies from microalgae, Renewable and Sustainable Energy Reviews. 24 (2013) 159-171. https://doi.org/10.1016/j.rser.2013.03.034.

[2] O. Pulz, W. Gross, Valuable products from biotechnology of microalgae, Applied Microbiology and Biotechnology. 65 (2004) 635-648.

[3] Y. Torres-Tiji, F.J. Fields, S.P. Mayfield, Microalgae as a future food source, Biotechnology Advances. 41 (2020) 107536. https://doi.org/10.1016/j.biotechadv.2020.107536.

[4] E. Waltz, Biotech's green gold?, Nat. Biotechnol. 27 (2009) 15-18. https://doi.org/10.1038/nbt0109-15.

[5] T. Ismagulova, A. Shebanova, O. Gorelova, O. Baulina, A. Solovchenko, A new simple method for quantification and locating $P$ and $N$ reserves in microalgal cells based on energy-filtered transmission electron microscopy (EFTEM) elemental maps, PLOS ONE. 13 (2018) e0208830. https://doi.org/10.1371/journal.pone.0208830.

[6] C. Uwizeye, J. Decelle, P.-H. Jouneau, B. Gallet, J.-B. Keck, C. Moriscot, F. Chevalier, N. Schieber, R. Templin, G. Curien, Y. Schwab, G. Schoehn, S. Zeeman, D. Falconet, G. Finazzi, In-cell quantitative structural imaging of phytoplankton using 3D electron microscopy, (2020). https://doi.org/10.1101/2020.05.19.104166.

[7] A.M. Barlow, A.D. Slepkov, A. Ridsdale, P.J. McGinn, A. Stolow, Label-free hyperspectral nonlinear optical microscopy of the biofuel micro-algae Haematococcus Pluvialis, Biomed. Opt. Express, BOE. 5 (2014) 3391-3402. https://doi.org/10.1364/BOE.5.003391.

[8] G. Binnig, C.F. Quate, C. Gerber, Atomic Force Microscope, Physical Review Letters. 56 (1986) 930-934.

[9] C. Formosa-Dague, M. Castelain, H. Martin-Yken, K. Dunker, E. Dague, M. Sletmoen, The Role of Glycans in Bacterial Adhesion to Mucosal Surfaces: How Can Single-Molecule Techniques Advance Our Understanding?, Microorganisms. 6 (2018) 39. https://doi.org/10.3390/microorganisms6020039.

[10] C. Formosa-Dague, R.E. Duval, E. Dague, Cell biology of microbes and pharmacology of antimicrobial drugs explored by Atomic Force Microscopy, Seminars in Cell \& Developmental Biology. (2017). https://doi.org/10.1016/j.semcdb.2017.06.022.

[11] Y.F. Dufrêne, T. Ando, R. Garcia, D. Alsteens, D. Martinez-Martin, A. Engel, C. Gerber, D.J. Müller, Imaging modes of atomic force microscopy for application in molecular and cell biology, Nat Nanotechnol. 12 (2017) 295-307. https://doi.org/10.1038/nnano.2017.45.

[12] C. Formosa-Dague, P. Speziale, T.J. Foster, J.A. Geoghegan, Y.F. Dufrêne, Zinc-dependent mechanical properties of Staphylococcus aureus biofilm-forming surface protein SasG, PNAS. 113 (2016) 410-415. https://doi.org/10.1073/pnas.1519265113.

[13] C. Formosa, V. Lachaize, C. Galés, M.P. Rols, H. Martin-Yken, J.M. François, R.E. Duval, E. Dague, Mapping HA-tagged protein at the surface of living cells by atomic force microscopy, J. Mol. Recognit. 28 (2015) 1-9. https://doi.org/10.1002/jmr.2407.

[14] C. Formosa-Dague, V. Gernigon, M. Castelain, F. Daboussi, P. Guiraud, Towards a better understanding of the flocculation/flotation mechanism of the marine microalgae Phaeodactylum tricornutum under increased pH using atomic force microscopy, Algal Research. 33 (2018) 369378. https://doi.org/10.1016/j.algal.2018.06.010. 
[15] F. Pillet, L. Chopinet, C. Formosa, É. Dague, Atomic Force Microscopy and pharmacology: From microbiology to cancerology, Biochimica et Biophysica Acta (BBA) - General Subjects. 1840 (2014) 1028-1050. https://doi.org/10.1016/j.bbagen.2013.11.019.

[16] J. Xiao, Y. Dufrêne, Optical and force nanoscopy in microbiology, Nature Microbiolgy. (2016).

[17] L. Chopinet, C. Formosa, M.P. Rols, R.E. Duval, E. Dague, Imaging living cells surface and quantifying its properties at high resolution using AFM in QI ${ }^{\mathrm{TM}}$ mode, Micron. 48 (2013) 26-33. https://doi.org/10.1016/j.micron.2013.02.003.

[18] S.A. Crawford, M.J. Higgins, P. Mulvaney, R. Wetherbee, Nanostructure of the Diatom Frustule as Revealed by Atomic Force and Scanning Electron Microscopy, Journal of Phycology. 37 (2001) 543-554. https://doi.org/10.1046/j.1529-8817.2001.037004543.x.

[19] I.C. Gebeshuber, J.H. Kindt, J.B. Thompson, Y.D. Amo, H. Stachelberger, M.A. Brzezinski, G.D. Stucky, D.E. Morse, P.K. Hansma, Atomic force microscopy study of living diatoms in ambient conditions, Journal of Microscopy. 212 (2003) 292-299. https://doi.org/10.1111/j.13652818.2003.01275.x.

[20] G. Francius, B. Tesson, E. Dague, V. Martin-Jézéquel, Y.F. Dufrêne, Nanostructure and nanomechanics of live Phaeodactylum tricornutum morphotypes, Environmental Microbiology. 10 (2008) 1344-1356. https://doi.org/10.1111/j.1462-2920.2007.01551.x.

[21] G. Pletikapić, A. Berquand, T.M. Radić, V. Svetličić, Quantitative Nanomechanical Mapping of Marine Diatom in Seawater Using Peak Force Tapping Atomic Force Microscopy1, Journal of Phycology. 48 (2012) 174-185. https://doi.org/10.1111/j.1529-8817.2011.01093.x.

[22] G. Pletikapić, V. Žutić, I.V. Vrček, V. Svetličić, Atomic force microscopy characterization of silver nanoparticles interactions with marine diatom cells and extracellular polymeric substance, Journal of Molecular Recognition. 25 (2012) 309-317. https://doi.org/10.1002/jmr.2177.

[23] A.I. Salimon, P.V. Sapozhnikov, J. Everaerts, O. Yu. Kalinina, C. Besnard, C. Papadaki, J. Cvjetinovic, E.S. Statnik, Y. Kan, P. Aggrey, V. Kalyaev, M. Lukashova, P. Somov, A.M. Korsunsky, A Mini-Atlas of diatom frustule electron microscopy images at different magnifications, Materials Today: Proceedings. 33 (2020) 1924-1933. https://doi.org/10.1016/j.matpr.2020.05.602.

[24] E.M. Eslick, M.J. Beilby, A.R. Moon, A study of the native cell wall structures of the marine alga Ventricaria ventricosa (Siphonocladales, Chlorophyceae) using atomic force microscopy, Microscopy. 63 (2014) 131-140. https://doi.org/10.1093/jmicro/dft083.

[25] I. Demir, J. Blockx, E. Dague, P. Guiraud, W. Thielemans, K. Muylaert, C. Formosa-Dague, Nanoscale Evidence Unravels Microalgae Flocculation Mechanism Induced by Chitosan, ACS Appl. Bio Mater. 3 (2020) 8446-8459. https://doi.org/10.1021/acsabm.0c00772.

[26] F. Pillet, E. Dague, J. Pečar Ilić, I. Ružić, M.-P. Rols, N. Ivošević DeNardis, Changes in nanomechanical properties and adhesion dynamics of algal cells during their growth, Bioelectrochemistry. 127 (2019) 154-162. https://doi.org/voelcker.

[27] C. Delattre, G. Pierre, C. Laroche, P. Michaud, Production, extraction and characterization of microalgal and cyanobacterial exopolysaccharides, Biotechnology Advances. 34 (2016) 11591179. https://doi.org/10.1016/j.biotechadv.2016.08.001.

[28] M.F. de J. Raposo, R.M.S.C. de Morais, A.M.M. Bernardo de Morais, Bioactivity and applications of sulphated polysaccharides from marine microalgae, Mar Drugs. 11 (2013) 233-252. https://doi.org/10.3390/md11010233.

[29] J. Cybulska, M. Halaj, V. Cepák, J. Lukavský, P. Capek, Nanostructure features of microalgae biopolymer, Starch - Stärke. 68 (2016) 629-636. https://doi.org/10.1002/star.201500159.

[30] L. Chopinet, C. Formosa, M.P. Rols, R.E. Duval, E. Dague, Imaging living cells surface and quantifying its properties at high resolution using AFM in QI ${ }^{\mathrm{TM}}$ mode, Micron. 48 (2013) 26-33. https://doi.org/10.1016/j.micron.2013.02.003.

[31] J.B. Vergnes, V. Gernigon, P. Guiraud, C. Formosa-Dague, Bicarbonate Concentration Induces Production of Exopolysaccharides by Arthrospira platensis That Mediate Bioflocculation and Enhance Flotation Harvesting Efficiency, ACS Sustainable Chem. Eng. 7 (2019) 13796-13804. https://doi.org/10.1021/acssuschemeng.9b01591. 
[32] C. Formosa, M. Grare, R.E. Duval, E. Dague, Nanoscale effects of antibiotics on P. aeruginosa, Nanomedicine: Nanotechnology, Biology and Medicine. 8 (2012) 12-16. https://doi.org/10.1016/j.nano.2011.09.009.

[33] C. Formosa, M. Schiavone, H. Martin-Yken, J.M. François, R.E. Duval, E. Dague, Nanoscale Effects of Caspofungin against Two Yeast Species, Saccharomyces cerevisiae and Candida albicans, Antimicrob. Agents Chemother. 57 (2013) 3498-3506. https://doi.org/10.1128/AAC.00105-13.

[34] Y. Xiao, Y. Cheng, P. He, X. Wu, Z. Li, New insights into external layers of cyanobacteria and microalgae based on multiscale analysis of AFM force-distance curves, Science of The Total Environment. 774 (2021) 145680. https://doi.org/10.1016/j.scitotenv.2021.145680.

[35] I.C. Gebeshuber, J.B. Thompson, Y.D. Amo, H. Stachelberger, J.H. Kindt, In vivo nanoscale atomic force microscopy investigation of diatom adhesion properties, Materials Science and Technology. 18 (2002) 763-766. https://doi.org/10.1179/026708302225003857.

[36] M.J. Higgins, S.A. Crawford, P. Mulvaney, R. Wetherbee, Characterization of the Adhesive Mucilages Secreted by Live Diatom Cells using Atomic Force Microscopy, Protist. 153 (2002) 2538. https://doi.org/10.1078/1434-4610-00080.

[37] M.J. Higgins, P. Molino, P. Mulvaney, R. Wetherbee, The Structure and Nanomechanical Properties of the Adhesive Mucilage That Mediates Diatom-Substratum Adhesion and Motility1, Journal of Phycology. 39 (2003) 1181-1193. https://doi.org/10.1111/j.0022-3646.2003.03-027.x.

[38] B.H.J. Yap, S.A. Crawford, R.R. Dagastine, P.J. Scales, G.J.O. Martin, Nitrogen deprivation of microalgae: effect on cell size, cell wall thickness, cell strength, and resistance to mechanical disruption, Journal of Industrial Microbiology and Biotechnology. 43 (2016) 1671-1680. https://doi.org/10.1007/s10295-016-1848-1.

[39] A.K. Lee, D.M. Lewis, P.J. Ashman, Force and energy requirement for microalgal cell disruption: An atomic force microscope evaluation, Bioresource Technology. 128 (2013) 199-206. https://doi.org/10.1016/j.biortech.2012.10.032.

[40] K.M. Warren, J.N. Mpagazehe, P.R. LeDuc, C.F. Higgs, Probing the elastic response of microalga Scenedesmus dimorphus in dry and aqueous environments through atomic force microscopy, Appl. Phys. Lett. 105 (2014) 163701. https://doi.org/10.1063/1.4898636.

[41] A. Landels, T.A. Beacham, C.T. Evans, G. Carnovale, S. Raikova, I.S. Cole, P. Goddard, C. Chuck, M.J. Allen, Improving electrocoagulation floatation for harvesting microalgae, Algal Research. 39 (2019) 101446. https://doi.org/10.1016/j.algal.2019.101446.

[42] T.M. Nolte, N.B. Hartmann, J.M. Kleijn, J. Garnæs, D. van de Meent, A. Jan Hendriks, A. Baun, The toxicity of plastic nanoparticles to green algae as influenced by surface modification, medium hardness and cellular adsorption, Aquatic Toxicology. 183 (2017) 11-20. https://doi.org/10.1016/j.aquatox.2016.12.005.

[43] N. Ivošević DeNardis, J. Pečar Ilić, I. Ružić, N. Novosel, T. Mišić Radić, A. Weber, D. Kasum, Z. Pavlinska, R.K. Balogh, B. Hajdu, A. Marček Chorvátová, B. Gyurcsik, Algal cell response to laboratory-induced cadmium stress: a multimethod approach, Eur Biophys J. 48 (2019) 231-248. https://doi.org/10.1007/s00249-019-01347-6.

[44] J. Ma, B. Zhou, F. Chen, K. Pan, How marine diatoms cope with metal challenge: Insights from the morphotype-dependent metal tolerance in Phaeodactylum tricornutum, Ecotoxicology and Environmental Safety. 208 (2021) 111715. https://doi.org/10.1016/j.ecoenv.2020.111715.

[45] J. Ma, B. Zhou, D. Duan, K. Pan, Salinity-dependent nanostructures and composition of cell surface and its relation to Cd toxicity in an estuarine diatom, Chemosphere. 215 (2019) 807-814. https://doi.org/10.1016/j.chemosphere.2018.10.128.

[46] C.T. Kreis, M. Le Blay, C. Linne, M.M. Makowski, O. Bäumchen, Adhesion of Chlamydomonas microalgae to surfaces is switchable by light, Nature Phys. 14 (2018) 45-49. https://doi.org/10.1038/nphys4258.

[47] A. Besson, C. Formosa-Dague, P. Guiraud, Flocculation-flotation harvesting mechanism of Dunaliella salina: From nanoscale interpretation to industrial optimization, Water Research. 155 (2019) 352-361. https://doi.org/10.1016/j.watres.2019.02.043. 
[48] C. Feuillie, C. Formosa-Dague, L.M.C. Hays, O. Vervaeck, S. Derclaye, M.P. Brennan, T.J. Foster, J.A. Geoghegan, Y.F. Dufrêne, Molecular interactions and inhibition of the staphylococcal biofilmforming protein SdrC, Proc Natl Acad Sci U S A. 114 (2017) 3738-3743. https://doi.org/10.1073/pnas.1616805114.

[49] E. Dague, D. Alsteens, J.-P. Latgé, C. Verbelen, D. Raze, A.R. Baulard, Y.F. Dufrêne, Chemical force microscopy of single live cells, Nano Lett. 7 (2007) 3026-3030. https://doi.org/10.1021/nl071476k.

[50] A. Viljoen, F. Viela, L. Kremer, Y. F. Dufrêne, Fast chemical force microscopy demonstrates that glycopeptidolipids define nanodomains of varying hydrophobicity on mycobacteria, Nanoscale Horizons. 5 (2020) 944-953. https://doi.org/10.1039/C9NH00736A.

[51] A. Meister, M. Gabi, P. Behr, P. Studer, J. Vörös, P. Niedermann, J. Bitterli, J. Polesel-Maris, M. Liley, H. Heinzelmann, T. Zambelli, FluidFM: Combining Atomic Force Microscopy and Nanofluidics in a Universal Liquid Delivery System for Single Cell Applications and Beyond, Nano Lett. 9 (2009) 2501-2507. https://doi.org/10.1021/nl901384x.

[52] E. Potthoff, O. Guillaume-Gentil, D. Ossola, J. Polesel-Maris, S. LeibundGut-Landmann, T. Zambelli, J.A. Vorholt, Rapid and Serial Quantification of Adhesion Forces of Yeast and Mammalian Cells, PLOS ONE. 7 (2012) e52712. https://doi.org/10.1371/journal.pone.0052712.

[53] E. Potthoff, D. Ossola, T. Zambelli, J.A. Vorholt, Bacterial adhesion force quantification by fluidic force microscopy, Nanoscale. 7 (2015) 4070-4079. https://doi.org/10.1039/C4NR06495J.

[54] O. Guillaume-Gentil, T. Rey, P. Kiefer, A.J. Ibáñez, R. Steinhoff, R. Brönnimann, L. Dorwling-Carter, T. Zambelli, R. Zenobi, J.A. Vorholt, Single-Cell Mass Spectrometry of Metabolites Extracted from Live Cells by Fluidic Force Microscopy, Anal. Chem. 89 (2017) 5017-5023. https://doi.org/10.1021/acs.analchem.7b00367.

[55] A. Saha-Shah, A.E. Weber, J.A. Karty, S.J. Ray, G.M. Hieftje, L.A. Baker, Nanopipettes: probes for local sample analysis, Chem. Sci. 6 (2015) 3334-3341. https://doi.org/10.1039/C5SC00668F.

[56] I. Demir, I. Lüchtefeld, C. Lemen, E. Dague, P. Guiraud, T. Zambelli, C. Formosa-Dague, Probing the interactions between air bubbles and (bio)interfaces at the nanoscale using FluidFM technology, Journal of Colloid and Interface Science. 604 (2021) 785-797. https://doi.org/10.1016/j.jcis.2021.07.036.

[57] A. Deniset-Besseau, C.B. Prater, M.-J. Virolle, A. Dazzi, Monitoring TriAcylGlycerols Accumulation by Atomic Force Microscopy Based Infrared Spectroscopy in Streptomyces Species for Biodiesel Applications, J. Phys. Chem. Lett. 5 (2014) 654-658. https://doi.org/10.1021/jz402393a.

[58] C.T. Evans, S.J. Baldock, J.G. Hardy, O. Payton, L. Picco, M.J. Allen, A Non-Destructive, Tuneable Method to Isolate Live Cells for High-Speed AFM Analysis, Microorganisms. 9 (2021) 680. https://doi.org/10.3390/microorganisms9040680. 